\title{
Temperature control of water-bath system in presence of constraints by using MPC
}

\author{
Sohaib Aslam *, Sundas Hannan, Waheed Zafar, Muhammad Umar Sajjad \\ Department of Electrical Engineering, Faculty of Engineering and Technology, Superior University, Lahore, Pakistan
}

\section{A R T I C L E IN F O}

\section{Article history:}

Received 15 September 2016

Received in revised form

28 November 2016

Accepted 1 December 2016

\section{Keywords:}

Model predictive control (MPC)

Proportional integral derivative (PID)

Prediction horizon (NP)

Control horizon (NC)

State space model

Aqua therapy

Constraints

Water-Bath

\begin{abstract}
A B S T R A C T
Water-Bath temperature control is of vital importance in several beverages product industries and in medical field for treatment of different diseases using aqua therapy and most of the control processes operate at constraints. PID and other non-optimization based control techniques do not handle input and output constraints effectively. MPC is an optimization based control technique with effective constraints handling ability in comparison to other control techniques. This paper is an application of sophisticated MPC for temperature control of Water-Bath system and presents the simulations of temperature control of water-bath system for medical use in aqua therapy. The results have been analyzed in three modes temperature control without constraints, with input constraints and with output constraints. In all three modes MPC effectively regulates the temperature within predetermined constraints limits. Finally robustness of MPC for temperature control of Water-Bath system is tested by varying the inlet flow rate of water and MPC again performs better by achieving the desired temperature efficiently.
\end{abstract}

(C) 2016 The Authors. Published by IASE. This is an open access article under the CC BY-NC-ND license (http://creativecommons.org/licenses/by-nc-nd/4.0/).

\section{Introduction}

Temperature is one of the key variables to be controlled in industrial processes. Temperature regulation of fluids to transport heat for particular use has leaded the industrial scenario for both power generation and process heating. Thermal fluids have numerous applications in industries of molding Processes, lamination, furniture, automotive manufacturing etc. Water-Bath temperature control is one of the major control process and has numerous applications in both food process industries and medical centers i-e Nestle, F\&N, Yeoh Hiop Seng, General district hospital Kifisia Greece etc. (Om et al., 2012; Lochaitis et al., 1992). Aqua therapy is the internal or external use of water in any of its forms (water, ice, steam) for health improvement or treatment of numerous diseases with specific temperatures, pressure, duration and it is one of the ways of treatment mostly used in domain of natural medicine (Moventhan and Nivethitha, 2014). It is the naturopathic treatment used on a huge scale in

\footnotetext{
* Corresponding Author.

Email Address: sohaib engg2000@yahoo.com (S. Aslam)

https://doi.org/10.21833/ijaas.2016.12.009

2313-626X/C) 2016 The Authors. Published by IASE.

This is an open access article under the CC BY-NC-ND license

(http://creativecommons.org/licenses/by-nc-nd/4.0/)
}

earlier cultures of China, India and Egypt for maintaining health, preventing and curing different diseases (Fleming and Gutknechet, 2010). Effect of warm water aqua therapy directly depends on the accuracy with which temperature of Water-Bath is controlled. Traditionally Proportional Integral Derivative (PID) control technique is used for temperature control systems. PID controller is one of the most commonly used controllers in industrial processes for its simplicity of usage it accounts for more than $90 \%$ of the installed automatic control systems. Although majority of control processes operate at constraints, but PID does not has the ability to handle input and output constraints effectively. Moreover, gains of PID have to be tuned again and again for added disturbance or change in system dynamics (Holkar and Waghmere, 2010). Solution to these issues is Model Predictive Control (MPC). MPC is an optimization based technique and its performance depends on selection of two important parameters prediction horizon $\left(\mathrm{N}_{\mathrm{p}}\right)$ and control horizon $\left(\mathrm{N}_{\mathrm{c}}\right)$. It optimizes the control sequence by minimizing the cost function at every sampling instant of time to reduce the difference between desired value and actual value of the system (Sohaib et al., 2016). In this research work simulations of Water-Bath temperature controller using MPC in three cases without constraints, with input constraints and with output constraints have analyzed by first modeling the water tank then 
implementing MPC and finally simulated in MATLAB. In section 2 Implementation of MPC is done. Section 3 and 4 presents simulation results and conclusion respectively

\section{Implementation of MPC}

MPC is a model based control technique and it uses process model to optimize the control vector without violating input or output constraints by minimizing the cost function. The basic structure of MPC is shown in Fig. 1 (Darandale et al., 2013).

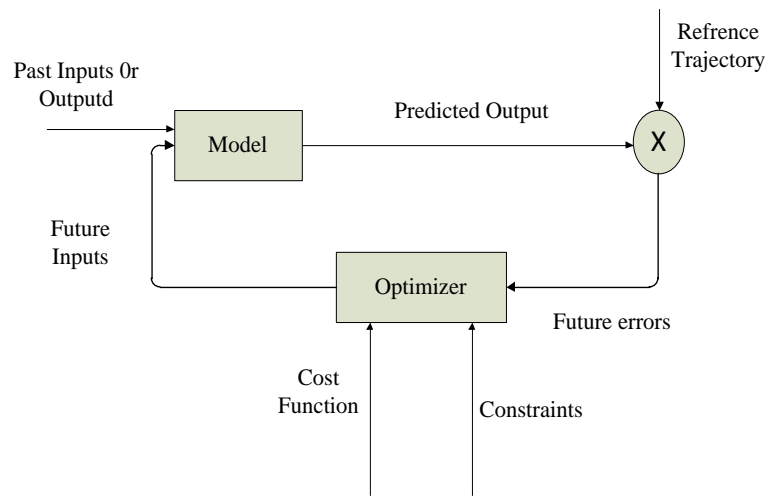

Fig. 1: Basic structure of MPC

The implementation of MPC is based on system modeling and optimizer. Optimizer is a mathematical function which optimizes the control signal by minimizing the cost function in presence of constraints. Outputs or past inputs in terms of temperature are presented at system model to get predicted output. The differences between the predicted output and reference value in form of errors are sent to optimizer which optimizes the future input and this procedure will remain continuous.

\subsection{System modeling}

The performance of heating process depends on the induction, maintenance and control. There are several heating methods used now a days in domestic and industrial processes i.e. direct heating, indirect heating, electric arc heating etc. In this research work direct resistance heating method is used in which immersion rod is dipped in the water tank. The heating capacity of immersion rod depends on its wattage power and the required wattage power for the heating rod is calculated by the Eq. 1:

$Q_{T}=\frac{W C \Delta T_{\text {water }}}{3412 . T}$

where, $Q_{T}$ is the heater wattage, $W$ is the weight of water, $C$ is the specific heat of water, $\Delta T$ is the change in temperature, and $T$ is the time required to raise temperature at desired level . In this case, $W$ is $33 \mathrm{lb}, C_{P}$ is $1 \mathrm{Btu} / \mathrm{lb} / \mathrm{F}, \Delta T$ is $140 \mathrm{~F}$, and $T$ is 1 hours. By substituting the values in Eq. 1 the required calculated wattage is given below:
$Q_{T}=\frac{88 * 1 * 140}{3412 * 1}=1.8 \mathrm{KW}$

As required power of immersion rod is $1.8 \mathrm{KW}$ so $2 \mathrm{KW}$ heating rod is selected. This immersion rod is used to regulate the temperature for Water-Bath system by using MPC control technique. Performance of MPC depends on how well the dynamics of system have been captured. The system model of water tank is shown in Fig. 2.

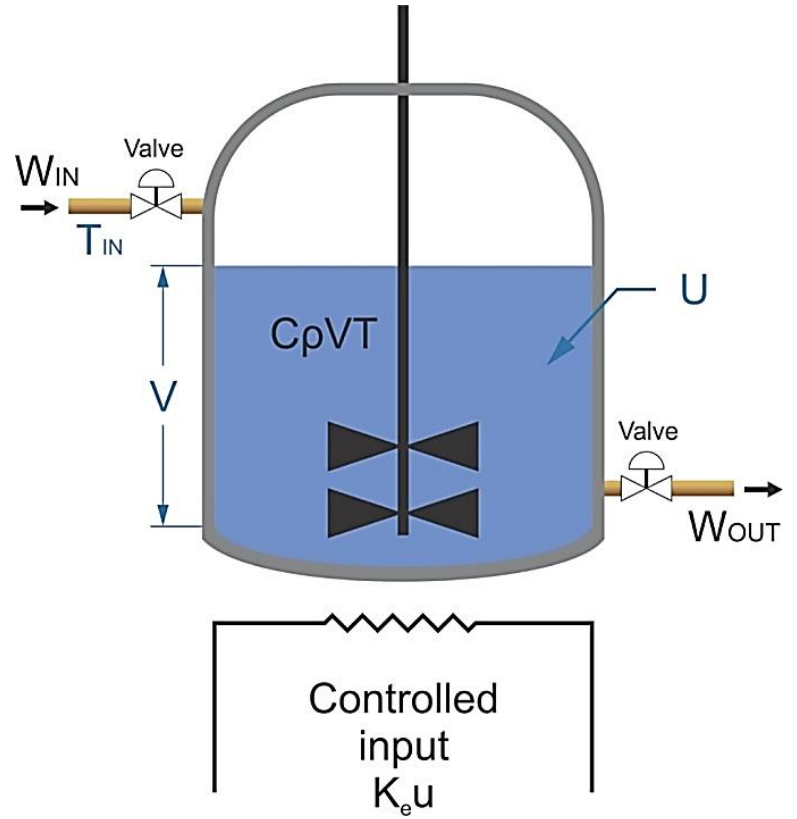

Fig. 2: System model

Where $K_{e} u$ is the input power, $\mathrm{C} \rho V T_{1}$ is the energy in the tank, $\rho$ is the density of water, $V$ is the volume, $T_{1}$ is the water temperature in the tank, $T_{\text {in }}$ is the inlet temperature, $U$ is the thermal conductivity, and $W$ is the mass flow rate of water. The parameter values of liquid tank are shown in Table 1.

Table 1: Parameters of System

\begin{tabular}{|c|c|c|}
\hline Number & Parameter & Value \\
\hline 1 & Weight & $\mathrm{K}_{\text {tau }}=40 \mathrm{Kg}$ \\
\hline 2 & Inlet Flow rate & $\mathrm{W}_{\mathrm{in}}=20 \mathrm{Kg} / \mathrm{min}$ \\
\hline 3 & Input Power & $\mathrm{Ke}_{\mathrm{e}}=2 \mathrm{KW}$ \\
\hline 4 & Specific Heat Capacity & $\mathrm{C}=4200 \mathrm{~J} / \mathrm{Kg}-\mathrm{K}$ \\
\hline 5 & Thermal Conductivity & $\mathrm{U}=0.6 \mathrm{~W} / \mathrm{mK} @$ \\
\hline 6 & Density & $\rho=1000 \mathrm{Kg} / \mathrm{m}^{3}$ \\
\hline 7 & Volume & $\mathrm{V}=0.20 \mathrm{~m}^{3}$ \\
\hline
\end{tabular}

The thermodynamic equation for water tank is Eq. 2:

$\frac{d\left(C \rho V T_{1}\right)}{d t}=K_{e} u+c W\left(T_{i n}-T_{1}\right)+U\left(T_{e n v}-T_{1}\right)$

by taking Laplace of Eq. 2 it becomes:

$C \rho V\left[s T_{1}(s)-T_{1 o}\right]=K_{e} u(s)+C W\left(T_{i n}(s)-T_{1}(s)\right)+$

$U\left(T_{\text {env }}(s)-T_{1}(s)\right)$

assuming that $T_{\text {in }}=T_{\text {env }}$ 
$C \rho V\left[s T_{1}(s)-T_{1 o}\right]=K_{e} u(s)+(C w+U)\left(T_{i n}(s)-T_{1}(s)\right)$

solving for $\mathrm{T}_{1}(\mathrm{~s}) \mathrm{Eq} .4$ becomes:

$$
\begin{aligned}
& T_{1}(s)=\frac{K_{e} / C W+U}{\frac{\rho V}{(w+U / c)} s+1} u(s)+\frac{1}{\frac{\rho V}{(w+U / c)} s+1} T_{i n}(s)+ \\
& \frac{\rho V /(W+U / C)}{\frac{\rho V}{(w+U / c)} s+1} T_{1 o}
\end{aligned}
$$

$\tau$ is the time delay between an excitation of heating element and the response of temperature sensor.

$T(t)=T_{1}(t-\tau)$

applying Laplace transformation to Eq. 6 it becomes:

$T(s)=T_{1}(s) e^{-\frac{K \tau}{W} s}$

by putting $T_{1}(s)$ in Eq. 7, the transfer function becomes:

$\frac{T(s)}{u(s)}=\frac{K_{e} / c w+U}{\frac{\rho V}{(w+U / c)} s+1} e^{-\frac{K_{\tau}}{w} s}$

here $\tau=\frac{K_{\tau}}{w}, \quad K_{u}=\frac{K_{e}}{c w+U}, \quad T_{k}=\frac{\rho V}{(w+U / c)}$ so transfer function $\mathrm{H}(\mathrm{s})$ becomes:

$H(s)=\frac{K_{u}}{T_{k} s+1} e^{-\tau s}$

By putting the values of parameters from Table 1 to Eq. 9, transfer function becomes:

$H(s)=\frac{0.02}{10 s+1} e^{0.03}$

the transfer function obtained is discretized by sampling interval of $10 \mathrm{sec}$ to convert it in discretetime state-space model as shown in Eqs. 11 and 12:

$x_{m}(k)=\left[\begin{array}{ccc}1 & 0 & 0 \\ 1 & 0 & 0 \\ 0 & 0 & 0\end{array}\right] x_{m}(k)+\left[\begin{array}{c}0.0200 \\ 0 \\ 0\end{array}\right] u(k)$

$y(k)=\left[\begin{array}{lll}1 & 0 & 0\end{array}\right] x_{m}(k)$

The Eqs. 11 and 12 represent the State Space Model (SSM) of the liquid tank that will be used in Fig. 1 to implement MPC temperature control of Water-Bath System.

\subsection{Optimization}

MPC optimizes the control vector $\Delta U$ by minimizing the cost function with predetermined constraints as shown in Eq. 13:

$J=\left(R_{S}-Y\right)^{T}\left(R_{S}-Y\right)+\Delta U^{T} \bar{R} \Delta U$

where, the first term in Eq. 13 minimizes the difference between the set-point signal and the predicted output while, second term reflects the importance given to change in control signal $\Delta \mathrm{U} . \overline{\mathrm{R}}$ is a diagonal matrix and $\overline{\mathrm{R}}=\mathrm{r}_{\mathrm{w}} \mathrm{I}_{\mathrm{N}_{\mathrm{c}} \times \mathrm{N}_{\mathrm{c}}} \cdot \mathrm{r}_{\mathrm{w}} \geq 0$ is a user defined tuning parameter for desired closed loop performance. When $r_{w}=0$ is used in cost function no importance is given to change in control signal and for large value of $r_{w}$ results in careful attention to change in control signal. The optimization of control vector is shown in Eq. 14 (Liuping, 2009).

$\Delta U=\left(\phi^{T} \phi+\bar{R}\right)^{-1} \phi^{T}\left(R_{S} F x\left(k_{i}\right)\right)$

where, $\mathrm{F}$ and $\phi$ are the vectors shown below:

$F=\left[\begin{array}{c}C A \\ C A^{2} \\ \cdot \\ C A^{N_{p}}\end{array}\right]$

and

$\phi=$
$\left[\begin{array}{cccccc}C B & 0 & 0 & 0 & \ldots & 0 \\ C A B & C B & 0 & 0 & \ldots & 0 \\ \vdots & C A B & C B & 0 & \ldots & 0 \\ C A^{N_{p}-1} B & C A^{N_{p}-2} B & C A^{N_{p}-3} B & \ldots & \ldots & C A^{N_{p}-N_{c}} B\end{array}\right]$

There are three major types of constraints two of them are applied at the control signal and change in control signal respectively while, the third one is applied at the output of the system. These constraints are of the form given below (Liuping, 2009).

$\Delta U^{\min } \leq \Delta U(k) \leq \Delta U^{\max }$

$u^{\min } \leq u(k) \leq u^{\max }$

$y^{\min } \leq y(k) \leq y^{\max }$

Traditionally, the constraints are imposed on the whole control vector and all constraints are expressed in terms of vector $\Delta U$ as shown below:

$\left[\begin{array}{c}u\left(k_{i}\right) \\ u\left(k_{i}+1\right) \\ u\left(k_{i}+2\right) \\ \vdots \\ u\left(k_{i}+N_{c}-1\right)\end{array}\right]=\left[\begin{array}{c}1 \\ 1 \\ 1 \\ \vdots \\ 1\end{array}\right] u\left(k_{i}-1\right)+$

$\left[\begin{array}{ccccc}1 & 0 & 0 & \ldots & 0 \\ 1 & 1 & 0 & \ldots & 0 \\ 1 & 1 & 1 & \ldots & 0 \\ \vdots & \vdots & \vdots & \ldots & 0 \\ 1 & 1 & \ldots & 1 & 1\end{array}\right]\left[\begin{array}{c}\Delta u\left(k_{i}\right) \\ \Delta u\left(k_{i}\right)+1 \\ \Delta u\left(k_{i}\right)+2 \\ \vdots \\ \Delta u\left(k_{i}\right)+N_{c}-1\end{array}\right]$

rearranging the Eq. 16 in a compact matrix form by relating $\mathrm{C}_{1}$ and $\mathrm{C}_{2}$ to appropriate matrices and subject to constraints for control signal as shown in equation below:

$-\left(C_{1} u\left(k_{i}-1\right)+C_{2} \Delta U\right) \leq-U^{\text {min }}$

$\left(C_{1} u\left(k_{i}-1\right)+C_{2} \Delta U\right) \leq U^{\max }$

where, $U^{\min }$ and $U^{\max }$ are column vectors with $\mathrm{N}_{\mathrm{c}}$ elements of $\mathrm{u}^{\min }$ and $\mathrm{u}^{\max }$ similarly for change in control signal constraints are: 
$-\Delta U \leq-\Delta U^{\min }$

$\Delta U \leq \Delta U^{\max }$

again, $\Delta U^{\min }$ and $\Delta U^{\max }$ are column vectors with $\mathrm{N}_{\mathrm{c}}$ elements. Similarly output constraints are presented in terms of $\Delta U$

$Y^{\min } \leq F x\left(k_{i}\right)+\phi \Delta U \leq Y^{\max }$

After minimizing the cost function for optimization of control vector, $\Delta U$ is subjected to the inequality constraints by following equation:

$\left[\begin{array}{l}M_{1} \\ M_{2} \\ M_{3}\end{array}\right] \Delta U \leq\left[\begin{array}{l}N_{1} \\ N_{2} \\ N_{3}\end{array}\right]$

where,

$$
\begin{gathered}
M_{1}=\left[\begin{array}{c}
-C_{2} \\
C_{2}
\end{array}\right] ; N_{1}=\left[\begin{array}{c}
-U^{\min }+C_{1} u\left(k_{i}-1\right) \\
U^{\max }-C_{1} u\left(k_{i}-1\right)
\end{array}\right] ; \\
M_{2}=\left[\begin{array}{c}
-1 \\
1
\end{array}\right] ; N_{2}=\left[\begin{array}{c}
-\Delta U^{\min } \\
\Delta U^{\max }
\end{array}\right] ; \\
M_{3}=\left[\begin{array}{c}
\phi \\
\phi
\end{array}\right] ; N_{3}=\left[\begin{array}{c}
-Y^{\min }+F x\left(k_{i}\right) \\
Y^{\max }-F x\left(k_{i}\right)
\end{array}\right]
\end{gathered}
$$

transforming the above Eq. in more compact form as shown in equation below and use it to find an optimized control without violating the constraints.

$M \Delta U \leq \gamma$

where, $\mathrm{M}$ is a vector of constraints with its rows equal to number of constraints and columns equal to dimension of $\Delta U$ (Liuping, 2009).

\section{Simulations based analysis}

The simulation results of Water-Bath temperature controller are analyzed in three cases ie without constraints, with input constraints and with output constraints. Finally, MPC is further evaluated under dynamic environment by varying inlet flow rates.

\subsection{MPC implementation flow chart}

Simulations of MPC are developed by first acquiring the state-space model (SSM) of water tank then include the design parameters $\mathrm{Nc}, \mathrm{Np}$, reference point and constraints. Finally, the cost function subject to constraints is minimized to optimize control vector which is further applied to SSM to get predicted output and this procedure continues until the desired set point is achieved. MPC implementation hierarchy is shown in Fig. 3.

\subsection{Simulation results}

The simulation results of water-Bath temperature control for different cases are presented below:

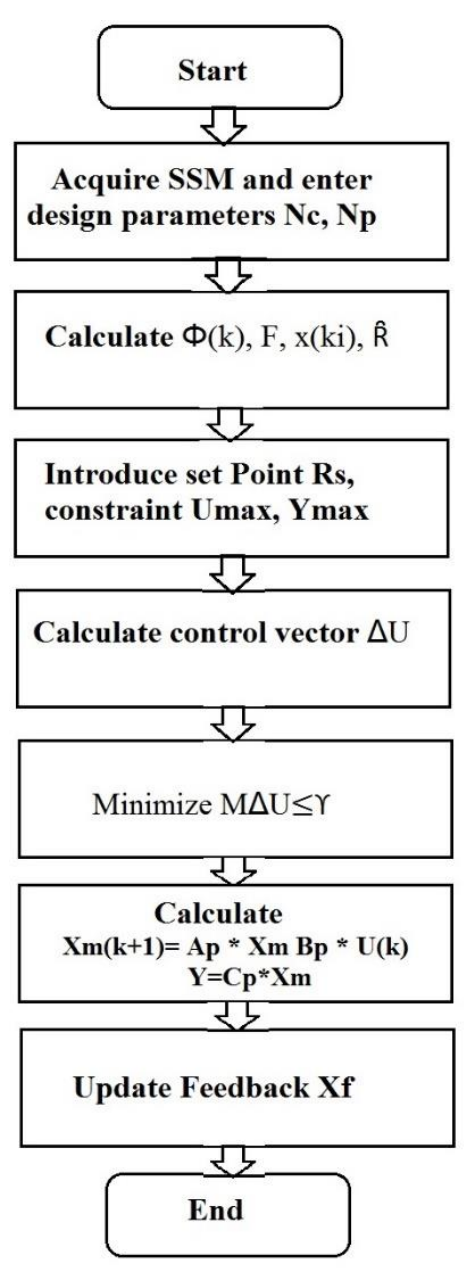

Fig. 3: MPC implementation hierarchy

\subsubsection{Water-bath temperature control without constraints}

The water-Bath temperature control is developed to be used in medical centers for the purpose of aqua therapy at different temperatures. Aqua therapy at $28^{\circ} \mathrm{C}$ not only provides treatment for bacterial coldwater diseases but also gives immunity against causative agent Flavobacterium psychrophilum (Sughara and Equichi, 2012). Head-out body immersion in Water-Bath at $38^{\circ} \mathrm{C}$ for 30 min results in decrease in blood viscosity which improves the blood pressure (Digeisi et al., 1986). Water immersion at $48{ }^{\circ} \mathrm{C}$ up to shoulder level results in increased oxygen $\left(\mathrm{O}_{2}\right)$ consumption level. Aqua therapy at $60{ }^{\circ} \mathrm{C}$ for $15 \mathrm{~min}$ improves cardiac function (Choukron and Varene, 1990). The simulation results of MPC with set-points of $28^{\circ} \mathrm{C}$, $38^{\circ} \mathrm{C}, 48^{\circ} \mathrm{C}$ and $60^{\circ} \mathrm{C}$ at different times are shown in Fig. 4. In the Fig. 4, MPC effectively regulates the temperature at different set-points for use in aqua therapy.

\subsubsection{Water-bath temperature control with input constraints}

The immersion heating rod is normally operated with $10 \%$ to $35 \%$ of safety factor. The $2 \mathrm{~kW}$ heating 
rod used in Water-Bath temperature controller is allowed to operate maximum at $1.7 \mathrm{~kW}$ with $15 \%$ safety factor, so the constraint on control signal is $\mathrm{U}^{\max }=1.7 \mathrm{~kW}$ with the desired set-point is $130^{\circ} \mathrm{C}$. The simulations have been presented without input constraints and with input constraints in Figs. 5 and 6 to compare the effect of constrained control signal.

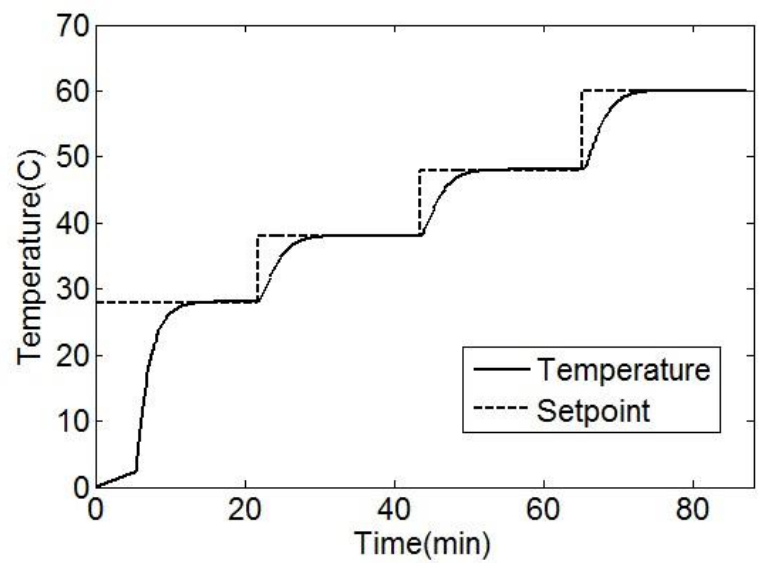

Fig. 4: Temperature control at different set-points

From Fig. 5 it is clear that Water-Bath temperature reaches the desired value of $130^{\circ} \mathrm{C}$ in 15.2 minutes and the control signal first gets to the peak value of $1.9 \mathrm{~kW}$ and finally gets off. After input constraint is applied on the amplitude of control signal temperature still reaches the desired value in 15.36 minutes so from Figs. 5 and 6 it is evident that MPC successfully regulates the temperature of Water-bath system without violating the input constraints but with only little time delay.

\subsubsection{Water-bath temperature control with output constraints}

In aqua therapy different temperature for Waterbath is required to cure different diseases but Water-Bath at temperature above $80^{\circ} \mathrm{C}$ becomes dangerous and causes skin burns immediately so temperature of water-Bath system should not exceed $80^{\circ} \mathrm{C}$. The output constraint is imposed at upper limit of $\mathrm{Y}^{\max }=80^{\circ} \mathrm{C}$ with set-point of $120^{\circ} \mathrm{C}$. The simulation results are shown in Fig. 7. Fig. 7 elaborates that output constraint is not violated.

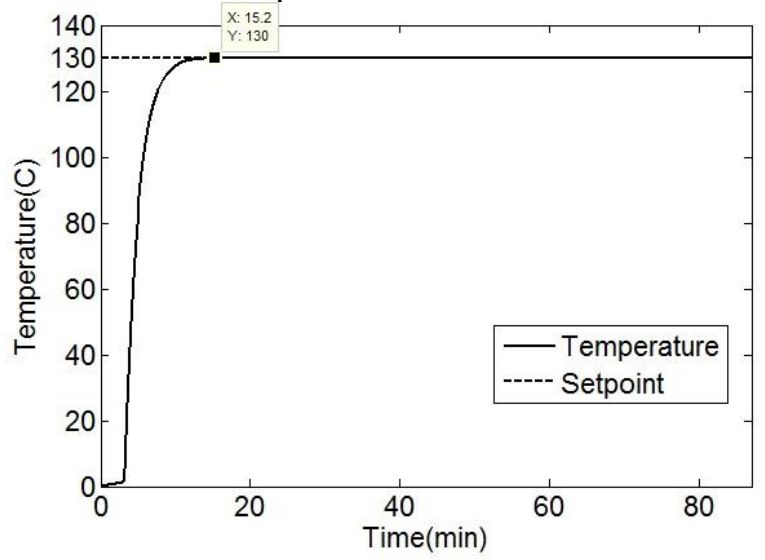

(a) Output

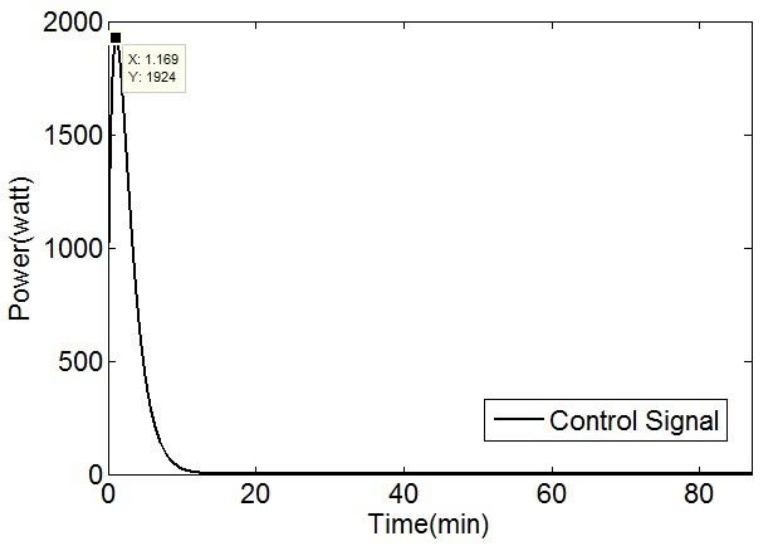

(b) Input

Fig. 5: Temperature control without input constraints

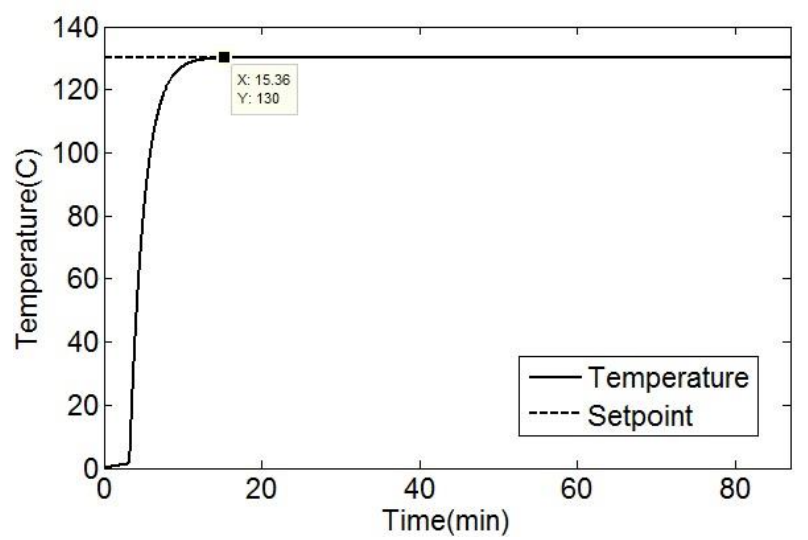

(a) Output

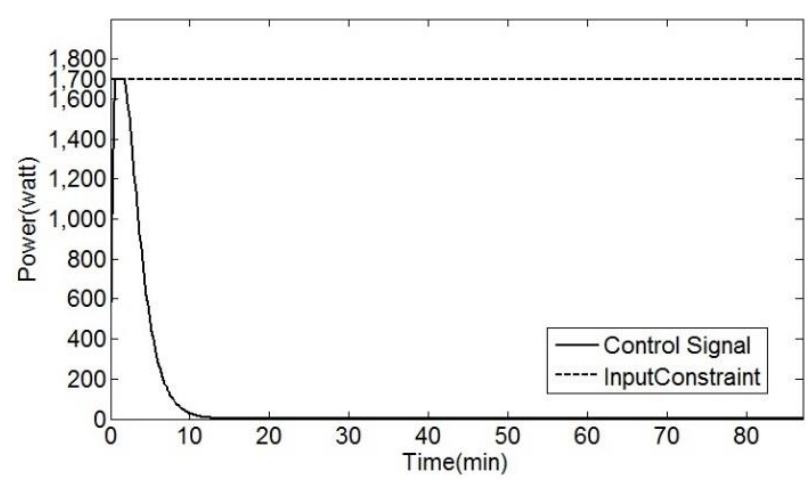

(b) Input

Fig. 6: Temperature control with input constraints

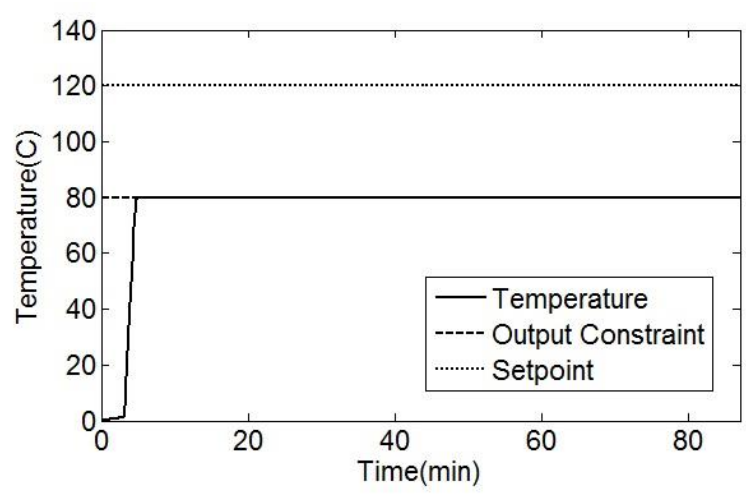

Fig. 7: Temperature control with output constraints

\subsubsection{Water-bath temperature control in dynamic environment}


Robustness of MPC is evaluated in dynamic environment by varying the inlet flow rate to the water tank. Initially inlet flow rate is fixed at $20 \mathrm{~kg} / \mathrm{min}$ for all above cases. Here firstly, MPC regulates the desired temperature with flow rate of $20 \mathrm{~kg} / \mathrm{min}$ then flow rate is varied at random to $30 \mathrm{~kg} / \mathrm{min}$ and then $40 \mathrm{~kg} / \mathrm{min}$ so the results have shown that MPC efficiently regulated the desired temperature but with little increase in time to reach the steady state at the desired temperature. The simulation results are shown in Fig. 8

From Fig. 8 it is clear that with inlet flow rates of $20 \mathrm{~kg} / \mathrm{min}, 30 \mathrm{~kg} / \mathrm{min}$ and $40 \mathrm{~kg} / \mathrm{min}$ controlled variable reaches the desired value of $60{ }^{\circ} \mathrm{C}$ in 15.87 min, $16.03 \mathrm{~min}$ and $16.2 \mathrm{~min}$. MPC performs better in dynamic environment by regulating the desired temperature of Water-Bath system with different flow rates as an added disturbance randomly.

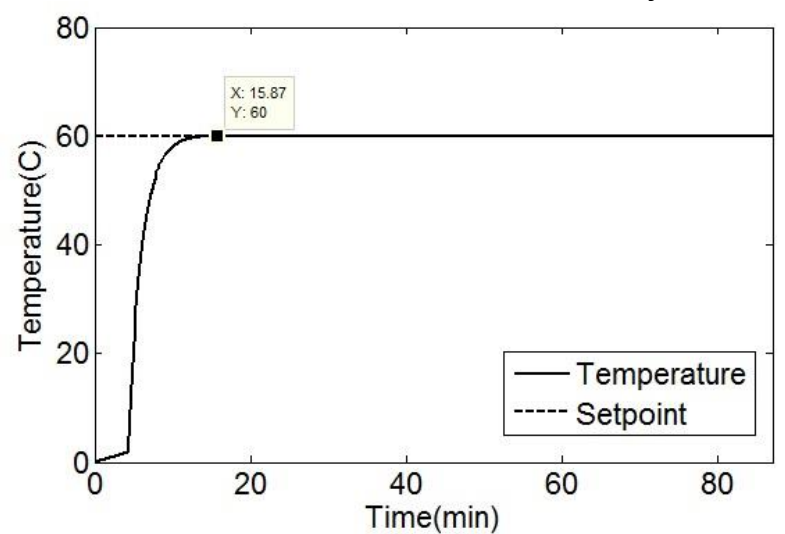

(a) Temperature regulation with $20 \mathrm{~kg} / \mathrm{min}$ inlet flow rate

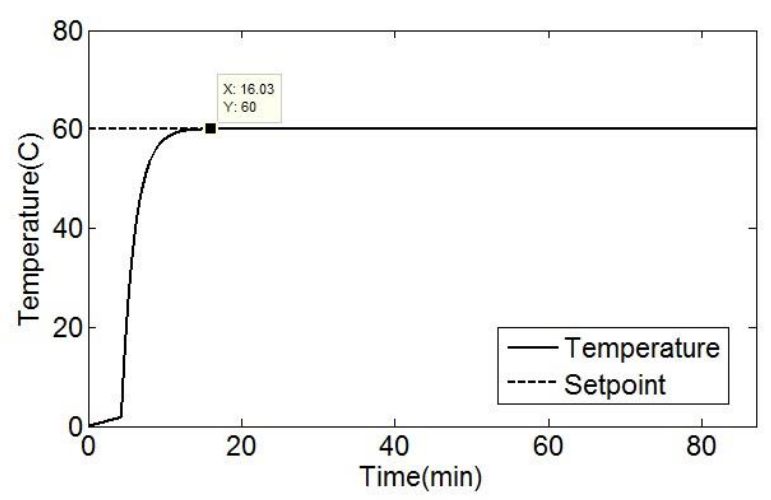

(b) Temperature regulation with $30 \mathrm{~kg} / \mathrm{min}$ inlet flow Rate

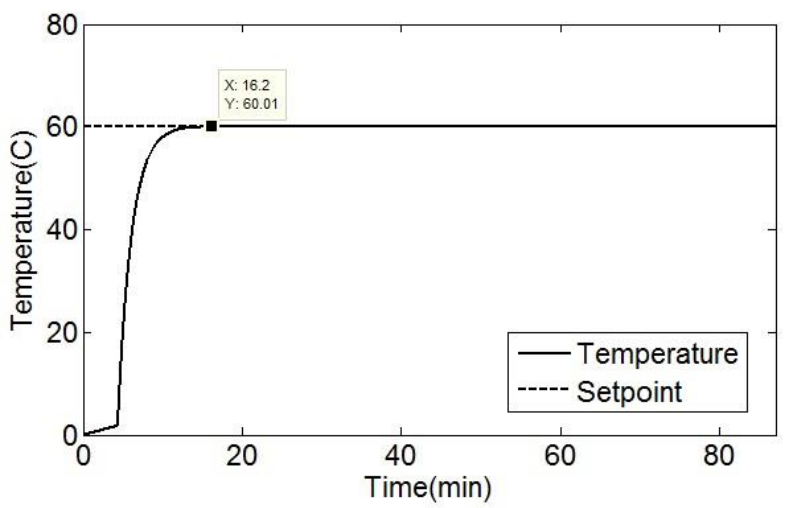

(c) Temperature regulation with $40 \mathrm{~kg} / \mathrm{min}$ inlet flow rate

Fig. 8: Temperature regulation with varying inlet flow rates

\section{Conclusion}

In this research work MPC based Water-Bath temperature controller is developed for purpose of aqua therapy in medical centers for treatment of different diseases. As PID is a simple structure control technique but it cannot effectively deal with input and output constraints therefore, simulation results of MPC have been analyzed in three modes temperature control without constraints, with input constraints and with output constraints. In all three modes MPC effectively regulates the temperature without violating the constraints. Finally, MPC effectively regulates the desired temperature of Water-Bath system in dynamic environment of variable inlet flow rate and proves to be a robust control technique. In future prospect MPC can be real time implemented on embedded device for Water-Bath temperature control system to test its real performance and moreover, research can be made to make this system more robust and energy efficient.

\section{References}

Choukron ML and Varene P (1990). Adjustment in Oxygen transports during head-out immersion in water at different temperatures. Journal of Applied Physiology, 68(4): 1475-1480.

Darandale RA, Kadu CB and Patil CY (2013). Design of Model Predictive control for temperature Process. In Proceedings of ELSEVIER International Conference on Advances in Signal Processing and Communication, Lucknow, India

Digeisi V, Cerchiai G and Mannini L (1986) Hemorheologic and blood cell changes in humans during partial immersion with a therapeutic method in $38^{\circ} \mathrm{C}$ water. Minerva Medica, $77(30$ 31): 1407-1411.

Fleming SA and Gutknechet NC (2010). Naturopathy and the primary care practice. Primary Care: Clinics in Office Practice, 37(1): 119-136

Holkar KS and Waghmere LM (2010). An overview of model predictive control. International Journal of Control and Automation, 3(4): 47-63.

Liuping W (2009). Model predictive control system design and implementation using MATLAB. $1^{\text {st }}$ ed., Springer, London, UK: 1-183.

Lochaitis A, Chalikitis S and Tzortzis C (1992). Hydrotherapy (bath therapy) as a treatment option in burns. Annals of the MBC, 5(2): 1-4.

Moventhan A and Nivethitha L (2014). Scientific evidence-based effects of hydrotherapy on various systems of the body. North American Journal of Medical Sciences, 6(5): 199-209.

Om PV, Rajesh S and Rajesh K (2012). Intelligent temperature controller for water-bath system. World Academy of Science, Engineering and 
Technology, International Journal of Computer, Information, Systems and Control Engineering, 6(9): 1179-1184.

Sohaib A, Sundas H and Arsalan H (2016). Effect of Laguerre function parameters on MPC performance for speed control of a DC motor.
Journal of Control Engineering and Technology, 6(1): 1-13.

Sughara K and Equichi M (2012). The use of warmed water treatment to induce protective immunity against the bacterial cold-water disease pathogen Flavobacterium Psychrophilim. Fish \& Shellfish Immunology, 32(3): 489-493. 